\title{
Effects of insulin resistance and testosterone on the participation of cyclooxygenase isoforms in vascular reactivity
}

This article was published in the following Dove Press journal:

Journal of Experimental Pharmacology

I December 2010

Number of times this article has been viewed

\author{
Harish Vasudevan' \\ Sally Lau' \\ Jihong Jiang ${ }^{2}$ \\ John $\mathrm{H}$ McNeill' \\ 'Division of Pharmacology and \\ Toxicology, Faculty of Pharmaceutical \\ Sciences, University of British \\ Columbia, Vancouver, British \\ Columbia, Canada; ${ }^{2}$ Pediatric \\ Oncology, Children and Women's \\ Hospital, Child and Family Research \\ Institute, Vancouver, British \\ Columbia, Canada
}

\begin{abstract}
Testosterone plays an important role in mediating hypertension and altered vascular reactivity associated with insulin resistance. In addition to other pathways, testosterone-dependent changes in aortic cyclooxygenase (COX-2) mRNA levels affect blood pressure following insulin resistance. However their effects on vascular tone are unclear. We studied the changes in contraction response to phenylephrine (PE) in the aorta and superior mesenteric artery (SMA) from intact and gonadectomized fructose-fed rats. Constriction response to PE was studied in tissues incubated with the COX-1 and COX-2-selective antagonists, SC-560 and NS-398, respectively, and indomethacin, in addition to assessing its role in endothelium-dependent relaxation. Finally changes in COX-2 protein expression and plasma thromboxane A2 (TXA2), a downstream vasoconstrictor metabolite of COX-2, were measured. In fructose-fed rats, castration prevented the increase in blood pressure but not insulin resistance. The involvement of COX-2 in mediating the alpha-adrenergic vasoconstriction was higher in intact rat aorta compared to COX-1, which was prevented by castration. However, in the SMA, COX-2 participation was dependent on testosterone alone. Fructose-induced attenuation of endothelial relaxation was restored by indomethacin, which suggests a pro-vasoconstrictor role for COX. Both diet and testosterone did not alter vascular COX-2 expression thus suggesting the involvement of downstream testosterone-dependent pathways. This is supported by increased plasma TXA2 in the castrated rats compared to intact rats. Isoform-specific actions of COX are tissue-selective in states of insulin resistance and involve potential testosterone-dependent downstream targets. Further studies are needed to investigate the role of androgens and insulin resistance in vascular arachidonic acid metabolism.
\end{abstract}

Keywords: insulin resistance, cyclooxygenase, testosterone, vascular reactivity, phenylephrine

\section{Introduction}

The role of insulin resistance in the induction of cardiovascular complications has been extensively studied. ${ }^{1}$ Resistance to insulin is associated with secondary complications such as endothelial dysfunction and impaired vasorelaxation, which leads to hypertension. ${ }^{2,3}$ We have previously demonstrated these effects in fructose-fed rats, a diet-induced model of the metabolic syndrome. ${ }^{2,3}$ Insulin resistance impairs the endothelium-dependent relaxation in superior mesenteric arteries, which is dependent on nitric oxide (NO). ${ }^{3}$ The development of endothelial dysfunction and elevated blood pressure is also dependent on the presence of testosterone. ${ }^{3,4}$ Testosterone replacement reverses the beneficial effects of castration to elevate the blood pressure, which is similar to that observed in intact fructose-fed rats. ${ }^{3}$ Although testosterone has been associated with upregulating several pro-constrictor pathways such as the renin-angiotensin system (RAS) ${ }^{5-9}$ and
Correspondence: John H McNeill Faculty of Pharmaceutical Sciences, University of British Columbia, 2I 46 East Mall,Vancouver, BC,V6T IZ3, Canada Tel + I 604-822-9373

Fax +| 604-822-800|

Email jmcneill@interchange.ubc.ca 
Cyp4A/20-hydroxyeicosatetranoic acid (20-HETE), ${ }^{10-13}$ almost none have been demonstrated in the fructose-fed rat vasculature. Most of the testosterone-dependent changes in vascular reactivity and blood pressure have been studied in the spontaneously hypertensive rat. ${ }^{1,6,11,14}$ Cyclooxygenase (COX) and testosterone have been demonstrated to influence vascular reactivity in long-term sucrose-fed rats. However so far only COX-2 expression has been shown to be elevated in the aorta of fructose-fed rats. ${ }^{4}$ Currently, sparse information is available regarding the roles of COX-1 and COX-2 in mediating agonist-induced vasoreactivity.

Vasoactive prostanoids such as prostaglandins, 8 -isoprostane, and thromboxane A2 (TXA2) are downstream metabolites of COX-1 and COX-2 action or arachidonic acid. ${ }^{15}$ Of the two COX isoforms, COX-2 has been implicated to have a greater influence on vascular tone as selective COX-2 inhibition attenuates responses to phenylephrine (PE) in the aortas of spontaneously hypertensive rats. ${ }^{16}$ In fructose-fed rats, following insulin resistance, elevations in both aortic COX-2 expression ${ }^{17}$ and TXA2, ${ }^{18}$ were observed. Selective inhibition of COX-2 in fructose-fed rats by celecoxib and nimesulide not only inhibited TXA2 and 8-isoprostane formation but also improved insulin sensitivity and decreased the blood pressure. ${ }^{15,19}$ These results implicate COX-2 as a key player in the development of insulin resistance and a subsequent increase in blood pressure.

In addition to a direct effect on insulin sensitivity and blood pressure, COX may also be an important downstream mediator of agonist-induced vasoconstriction. This is demonstrated by the involvement of COX in the attenuated responses to PE following angiotensin receptor blockade. ${ }^{16}$ In addition, Puyo et $\mathrm{a}^{20}$ have reported altered prostanoid levels in the mesenteric bed of fructose-fed rats in the presence of angiotensin-II and noradrenaline. COX is also a downstream target of endothelin-1 (ET-1), which has been implicated in mediating cardiovascular complications secondary to insulin resistance. ${ }^{17,21}$ Interestingly, recent evidence has demonstrated crosstalk between ET-1 and the RAS secondary to insulin resistance. ${ }^{22}$ Thus it may be possible that in an insulin-resistant milieu, both isoform-specific and/or nonspecific COX-dependent mechanisms may contribute to PEinduced vasoconstriction. Currently, there are no functional data to demonstrate the specific contributions of individual COX isoforms in that maintenance of vascular tone.

In this study, we had 3 main objectives: 1) to examine the effect of COX inhibition on endothelium-dependent relaxation, 2) to identify the individual contributions of COX-1 and COX-2 to PE-induced vasoconstriction in the superior mesenteric artery (SMA) and aorta of normal and fructose-fed rats, and 3) to determine whether testosterone affects the regulation of vascular reactivity by COX.

\section{Materials and methods}

Sixty-four male Wistar rats were obtained from Charles River, Montreal, Canada. Thirty-two rats had their testes surgically removed at the age of 5 weeks while the remaining 32 were sham-operated at the same age prior to shipment. The rats were maintained under regular light/dark cycle with ad libitum access to food and water. The rats were acclimated for 1 week in the animal facility at the Faculty of Pharmaceutical Sciences, University of British Columbia and cared for in accordance with the guidelines outlined by the Canadian Council on Animal Care (CCAC). The protocol for animal use was approved by the Animal Care Committee of the University of British Columbia. In each study, the starch in normal laboratory rat chow was replaced in $50 \%$ of animals with a diet enriched with fructose $(60 \%)$, which was obtained commercially as a preformulated diet (Teklad Labs, Madison, WI). This high-fructose containing diet has been shown in previous studies to induce insulin resistance and hypertension. ${ }^{23,24}$ The rats in the control groups ( $\mathrm{C}$ and $\left.\mathrm{G}\right)$ were fed standard laboratory rat chow.

\section{Experimental design}

In both studies rats were divided into 4 groups, sham-operated normal chow-fed control $(C ; n=8)$, sham-operated fructosefed $(\mathrm{F} ; \mathrm{n}=8)$, gonadectomized normal chow-fed $(\mathrm{G} ; \mathrm{n}=8)$, and gonadectomized-fructose-fed (GF; $\mathrm{n}=8)$.

Following 9 weeks of fructose feeding, an oral glucose tolerance test was performed on the rats as previously described. ${ }^{25}$ At termination, the rats were euthanized by a single injection of $65 \mathrm{mg} / \mathrm{kg}$ intraperitoneal injection of pentobarbital followed by opening of the chest cavity. Blood was collected by cardiac puncture for determination of plasma testosterone and TXA2 levels. In study 1, the SMA was isolated and cleaned of excess adipose and connective tissues for measuring changes in vascular reactivity. In study 2, both SMA and thoracic aorta were isolated for vascular reactivity experiments.

\section{Measurement of blood pressure and assessment of insulin resistance/sensitivity}

Systolic blood pressure was measured in conscious rats prior to the start of and after 9 weeks of fructose feeding using the indirect noninvasive tail-cuff method as previously described. 
Insulin sensitivity was calculated following the oral glucose challenge using the formula of Matsuda and DeFronzo using 100 as constant: ISI $=100 /$ square root of $[$ (fasting glucose $\times$ fasting insulin $) \times($ mean glucose $\times$ mean insulin $)]{ }^{26}$

\section{Studies on vascular reactivity Study I}

Endothelium-intact tissue rings each of length 3 to $4 \mathrm{~mm}$ were dissected from the SMA and appended onto glass hooks, which were then mounted in a $20 \mathrm{~mL}$ isolated tissue bath containing oxygenated $\left(95 \% \mathrm{O}_{2}\right.$ and $\left.5 \% \mathrm{CO}_{2}\right) \mathrm{Krebs}$ Ringer buffer at $37^{\circ} \mathrm{C}$ as described previously. ${ }^{18,27}$ Following an initial challenge with $40 \mathrm{mM}$ potassium chloride $(\mathrm{KCl})$, changes in endothelium-dependent relaxation were assessed in the isolated SMA. Briefly, relaxation to increasing doses of acetylcholine (ACh) $\left(10^{-9}-10^{-4} \mathrm{M}\right)$ was determined in tissues precontracted with the $\mathrm{ED}_{70}$ dose of PE. The vessels were then incubated with $10^{-5} \mathrm{M}$ indomethacin for 20 minutes and the above-described procedure was repeated. Results are reported as percentage relaxation of contraction produced by PE.

\section{Study 2}

Following assessment of endothelial integrity in the presence of $1 \mu \mathrm{M}$ ACh, the aorta and SMA were assessed for changes in contractile responses to increasing concentrations of $\mathrm{PE}$ $\left(10^{-9}-10^{-4} \mathrm{M}\right)$, in the absence and presence of the following drugs: 1) a selective COX-2 inhibitor (NS-398; $10^{-6} \mathrm{M}$ ), 2) a selective COX-1 inhibitor (SC-560; $10^{-5} \mathrm{M}$, and 3 ) a nonselective COX inhibitor (indomethacin; $10^{-5} \mathrm{M}$ ). NS-398 has been shown to exhibit a 100 -fold greater selectivity to COX-2 over COX-1. ${ }^{28}$ Similarly SC-560 selectively inhibits COX-1 as the $\mathrm{IC}_{50}$ values are 1000-fold higher than those for COX-2. ${ }^{29}$ Our aim was to individually inhibit COX-2 and COX-1 followed by total blockade with indomethacin to provide an insight into the role played by each isoform in vascular reactivity.

Briefly, following the challenge with $40 \mathrm{mM} \mathrm{KCl}$ and confirmation of endothelial integrity, a basal cumulative response curve to $\mathrm{PE}$ was obtained. Post equilibration, the tissues were incubated individually with NS-398 $\left(10^{-6} \mathrm{M}\right)$ followed by SC-560 $\left(10^{-5} \mathrm{M}\right)$ and indomethacin $\left(10^{-5} \mathrm{M}\right)$ (in that order) for 20 minutes each. For example, after obtaining responses to $\mathrm{PE}$ in the presence of NS-398, the tissues were washed with Krebs Ringer until the contraction returned to baseline values. Upon equilibration, they were then treated with SC-560 and the process was repeated for both SC-560 and indomethacin.
Additionally, a second ring from the same tissue was used as a time control.

At the end of the experiment, the tissues were blotted onto KimWipes $^{\circledR}$ (Kimberley-Clark, Irving, TX) and weighed. Responses to PE were reported as $\mathrm{mg} / \mathrm{mm}^{2}$ tension in the SMA and as percentage of maximum $\mathrm{KCl}$ contraction in the aorta.

\section{COX-2 protein expression}

Protein levels of COX-2 in the tissues were evaluated by Western blotting based on previously reports from our laboratory using rabbit polyclonal antibodies against COX-2 (Abcam, MA and Cell Signaling, Danvers, MA). ${ }^{17}$ Briefly protein lysates were prepared by homogenizing tissues in RIPA buffer. The proteins, with concentrations of 0.5 to $1 \mu \mathrm{g} / \mu \mathrm{L} / \mathrm{sample}$, were separated by electrophoresis and transferred onto PVDF membranes. Following blocking with 5\% nonfat milk, the membranes were incubated overnight at $4{ }^{\circ} \mathrm{C}$ with 1:5000 COX-2 antibody in BSA (bovine serum albumin-fraction 5 (Roche Diagnostics, QC, Canada). The membranes were then washed with TBS-T and incubated with horseradish peroxidase (HRP)-conjugated anti-rabbit secondary antibody (1:10,000 in 5\% nonfat milk) at room temperature for 1 hour. Following $3 \times 10$-minute washings with TBS-T, the membranes were developed in ECL reagent (ECL reagent A\&B; GE Life Sciences, QC, Canada). A monoclonal mouse antibody (1:2000; Abcam, MA) was used to determine glyceraldehyde 3-phosphate dehydrogenase (GAPDH) expression, which was used as control.

Changes in band densities were recorded using Image $J^{\mathrm{TM}}$ software. Sample band densities were normalized to their corresponding GAPDH band density to obtain a ratio. These values were in turn expressed relative to control (C), ie, assuming each $\mathrm{C}$ value to be 1 .

\section{Biochemical parameters}

Glucose was measured in the plasma using a Beckman glucose analyzer. Insulin was measured using radioimmunoassay kits from Linco, MO. Testosterone was measured in the plasma using a commercially available radioimmunoassay kit from MP Biomedicals (Solon, OH). Thromboxane B2 (TXB2), the stable metabolite of TXA2, was measured in the plasma using an EIA kit (GE Life Sciences).

\section{Chemicals and reagents}

All chemicals unless otherwise mentioned were of reagent grade and purchased from Sigma (St Louis, MO). Phenylephrine and acetylcholine were dissolved in Krebs Ringer while NS-398 and SC-560 were dissolved in dimethyl sulfoxide 
(DMSO). Indomethacin was dissolved in 10\% sodium bicarbonate $\left(\mathrm{Na}_{2} \mathrm{CO}_{3}\right)$ solution. $20 \mu \mathrm{L}$ of each drug solution was added to the bath during the study.

\section{Statistical analysis}

All data were analyzed using one-way analysis of variance (ANOVA). Data involving multiple time points were subject to the general linear model (GLM) ANOVA using the NCSS $2000^{\mathrm{TM}}$ statistical software (NCSS, Kaysville, UT). The Newman-Keuls test was used as a post hoc test. The value of $P<0.05$ was taken as the level of significance. All results are reported as mean \pm SEM.

\section{Results}

Statistical analysis of insulin sensitivity, plasma testosterone, and blood pressure showed no significant differences between the two studies. Therefore, we have combined the data from both studies and presented the values in a single table (Table 1).

Similar to previous reports from our laboratory, ${ }^{3}$ fructose decreased the insulin sensitivity as demonstrated by the decrease in insulin sensitivity index values in the fructosefed rats (F and GF) (Table 1).

Blood pressure was elevated in sham-operated fructosefed rats at the end of 9 weeks (F, $134 \pm 2 \mathrm{mmHg}$ vs $\mathrm{C}$, $113 \pm 2 \mathrm{mmHg} ; P<0.05)$. Fructose did not affect the blood pressure in gonadectomized animals (GF, $113 \pm 2 \mathrm{mmHg}$ ) (Table 1).

Testosterone was undetectable in gonadectomized rats. Fructose did not affect testosterone levels (Table 1).

\section{Vascular reactivity studies \\ Acetylcholine response}

Similar to previous reports from our laboratory, ${ }^{3}$ fructose feeding attenuated the relaxation to ACh in F but not in GF, suggesting the prevention of endothelial dysfunction in the

Table I Insulin sensitivity index, systolic blood pressure, and plasma testosterone in rats following fructose feeding

\begin{tabular}{llll}
\hline Groups & $\begin{array}{l}\text { Insulin } \\
\text { sensitivity } \\
\text { index }\end{array}$ & $\begin{array}{l}\text { Systolic blood } \\
\text { pressure } \\
(\mathbf{m m H g})\end{array}$ & $\begin{array}{l}\text { Plasma } \\
\text { testosterone } \\
(\mathbf{n g} / \mathbf{m L})\end{array}$ \\
\hline $\mathrm{C}$ & $12.0 \pm 0.8$ & $113 \pm 2$ & $2.2 \pm 0.4$ \\
$\mathrm{~F}$ & $8.3 \pm 0.8^{*}$ & $134 \pm 2^{\#}$ & $2.0 \pm 0.2$ \\
$\mathrm{G}$ & $15.2 \pm 1.0$ & $110 \pm 1$ & $<\mathrm{LLQ}$ \\
$\mathrm{GF}$ & $9.5 \pm 0.8^{*}$ & $113 \pm 2$ & $<\mathrm{LLQ}$ \\
\hline
\end{tabular}

Notes: The 4 experimental groups were control (C), fructose-fed (F), gonadectomized (G), and gonadectomized fructose-fed (GF). Values are presented as mean \pm SEM. Statistical analysis was done by one-way ANOVA followed by NewmanKeuls post hoc test. $* P<0.05 \mathrm{~F}$ and GF vs $C$ and G; ${ }^{\# P}<0.05$ F vs $C, G$, and GF. Abbreviation: $<L L Q$, not detected as below limit of quantitation. absence of testosterone (Figure 1A and 1B). Inhibition of $\mathrm{COX}$ by indomethacin ameliorated the relaxation to $\mathrm{ACh}$ in the SMA of intact fructose-fed rats. Indomethacin did not affect the relaxation in other groups as analyzed by 2-way ANOVA (Figure 2).

\section{Phenylephrine response}

In this experiment, contractile responses to PE over time did not change in the control vessels corresponding to treated vessels.

\section{Superior mesenteric artery}

Endothelium-intact vessels were used for these experiments. In the absence of inhibitors, responses to PE were unchanged in both intact and gonadectomized fructose-fed rats (Figure 3A).

Treatment with NS-398 attenuated the PE-induced vasoconstriction in both control and fructose-fed rats with
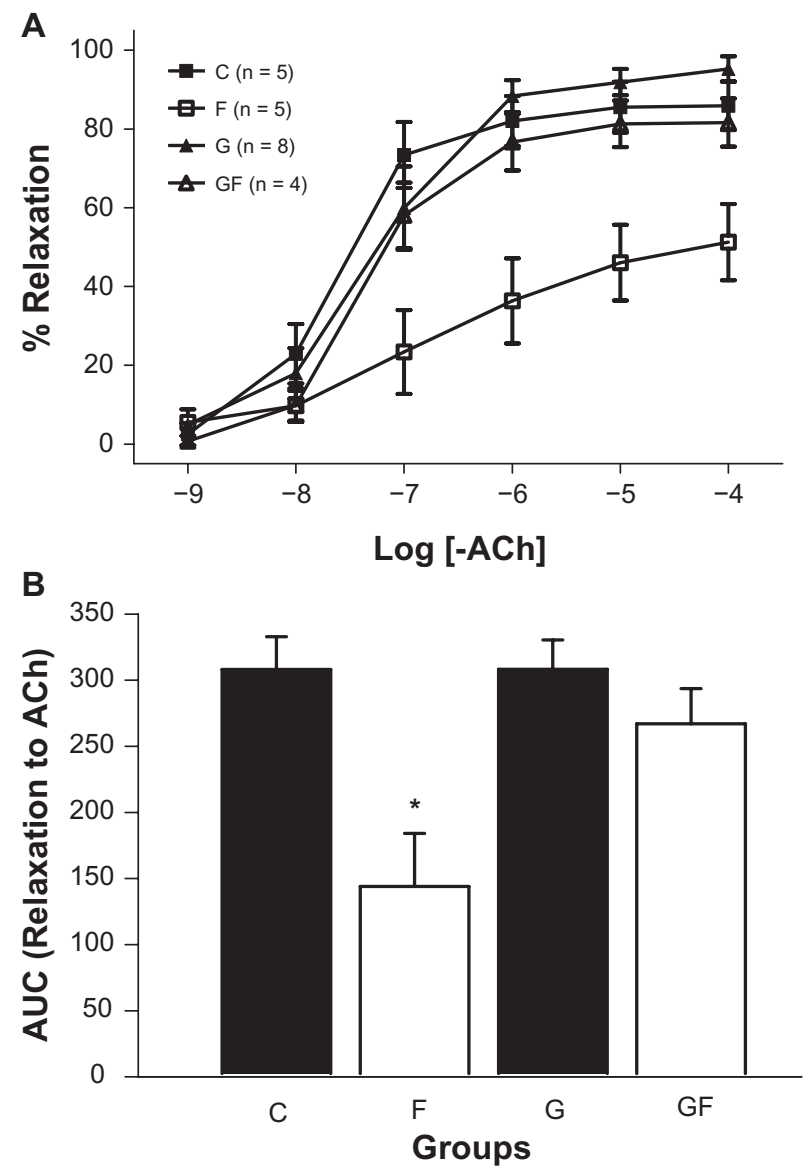

Figure I Fructose feeding attenuated the relaxation to acetylcholine in the superior mesenteric artery, which is prevented by gonadectomy. A) Relaxation responses were obtained to acetylcholine $\left(\mathrm{ACh}, 10^{-9}-10^{-4} \mathrm{~mol} / \mathrm{L}\right)$ after precontraction with $E D_{70}$ phenylephrine in the 4 experimental groups: control $(C)$, fructose-fed $(F)$, gonadectomized (G), and gonadectomized fructose-fed (GF). B) Shows area under the curve (AUC) values for the responses.

Notes: " $n$ " values are indicated on the graph. All values are presented as mean \pm SEM. $* P<0.05 \mathrm{~F}$ vs $\mathrm{C}, \mathrm{G}$, and GF. 


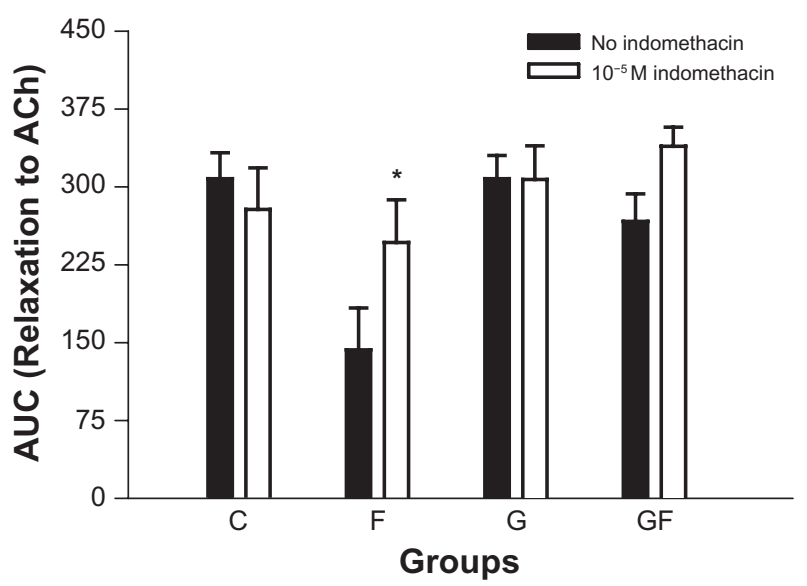

Figure 2 Inhibition of cyclooxygenase by indomethacin improved relaxation to acetylcholine (Ach) in intact but not gonadectomized fructose-fed rats. Responses to $\mathrm{ACh}$ were examined in the presence of $10^{-5} \mathrm{M}$ indomethacin. The 4 experimental groups were control $(C)$, fructose-fed $(F)$, gonadectomized $(G)$, and gonadectomized fructose-fed (GF). Subsequent to obtaining basal relaxation responses to $A C h$, tissues were washed with Krebs Ringer and incubated with indomethacin. Relaxation responses were obtained to $\left(\mathrm{ACh}, 10^{-9}-10^{-4} \mathrm{~mol} / \mathrm{L}\right)$ after precontraction with $\mathrm{ED}_{70}$ phenylephrine. Responses to ACh in C, F, G, and GF are compared in the presence of indomethacin (white bars) to relaxation in the absence of indomethacin (black bars). Inhibition of $\mathrm{COX}$ by indomethacin improved the relaxation to $\mathrm{ACh}$ in intact $\mathrm{F}$ rats but not $C, G$, and GF. Relaxation is shown as area under the curve (AUC) values. Notes: Results are shown as mean \pm SEM. $* P<0.05 \mathrm{~F}$ (black) vs F + INM (white).

intact testes as compared to the gonadectomized groups. Although there was no statistical significance observed in Figure $3 \mathrm{~B}$, the area under the curve values showed a difference between $\mathrm{G}$ and GF vs $\mathrm{C}$ and $\mathrm{F}$ (Table 2).

No statistical differences were observed in the contractile responses to $\mathrm{PE}$ following incubation with indomethacin (Figure 3C). However, in comparison with untreated controls, indomethacin attenuated the contraction to PE. Similar to NS-398, indomethacin did not affect the responses to PE in G and GF (G + INM: $18547 \pm 4282$ and GF + INM: $21210 \pm 6537)$. This suggests the presence of a testosteronedependent involvement of COX. In addition, the data point to selective COX-2 involvement in mediating physiological responses to $\mathrm{PE}$.

Treatment with SC-560, the selective COX-1 blocker, did not affect PE-induced vasoconstriction in any of the groups (Figure 3D). This suggests a lack of involvement for COX-1 in PE-induced constriction.

COX inhibition did not affect the $\mathrm{pD} 2$ values in tissues (Table 2). However, the changes in maximum concentration values $\left(\mathrm{R}_{\max }\right)$ mirrored the drug-dependent changes observed in the concentration response curves to PE discussed earlier (Table 2).

\section{Aorta}

Similar to the SMA, fructose feeding did not affect the responses to $\mathrm{PE}$ in isolated aorta (Figure 4A). In the presence of NS-398, PE-evoked contraction was unaffected in all groups except F (Figure 4B). NS-398 decreased the responses in $\mathrm{F}$ compared to basal values but not in $\mathrm{C}$, suggesting insulin resistance may be responsible for the augmented dependence on COX-2 in aorta (Table 3). COX-2 dependent modulation of constriction was absent in the gonadectomized rats where the degree of attenuation of PE-induced vasoconstriction was greater in $\mathrm{F}$ as compared to GF (Figure 4B).

Indomethacin produced a contraction pattern similar to that observed in presence of NS-398. Therefore while indomethacin did not affect the responses in $\mathrm{C}$, contraction to $\mathrm{PE}$ was attenuated in intact fructose-fed rats. Tissues from $G$ and GF were unaffected by the presence of indomethacin (Figure 4C). Similar to NS-398, PE-induced contraction was significantly lower only in $\mathrm{F}$ following indomethacin treatment (Table 3).

Responses to $\mathrm{PE}$ were unaffected in all groups following selective COX-1 blockade (Figure 4D). Further SC-560 did not affect the responses compared to basal values in any of the groups. This is similar to the results observed in SMA.

Similar to the SMA, pD2 values were unaffected in all groups. However, inhibition of $\mathrm{COX}$ attenuated the $\mathrm{R}_{\max }$ values in $\mathrm{F}$ but not $\mathrm{C}, \mathrm{G}$ and GF (Table 3).

\section{COX-2 protein expression}

In both the aorta and SMA, fructose and gonadectomy did not affect COX-2 expression (Figure 5A and 5B, respectively).

\section{Plasma TXB2 levels}

Levels of TXB2, the stable metabolite of TXA2, were the highest in gonadectomized fructose-fed rats as compared to other groups. Fructose feeding also slightly elevated the TXB2 in intact rats compared to controls (Figure 6).

\section{Discussion}

In the present study, in addition to confirming the effects of fructose diet and testosterone on insulin resistance and blood pressure, we report for the first time that in the presence of testosterone, insulin resistance increases the individual participation of COX-2 in mediating vasoconstriction to $\mathrm{PE}$ in the aorta. However, in this study, there was no change in the aortic COX-2 expression, which is not in agreement with previous reports from our laboratory. ${ }^{4,17}$ In the current study, rats were fed with fructose for 9 weeks, which was similar to the protocol by Jiang et $\mathrm{a}^{17}$ but was longer than the duration of fructose feeding in Song et al. ${ }^{4}$ While we are unable to explain this variation, one possibility would be to examine 
A

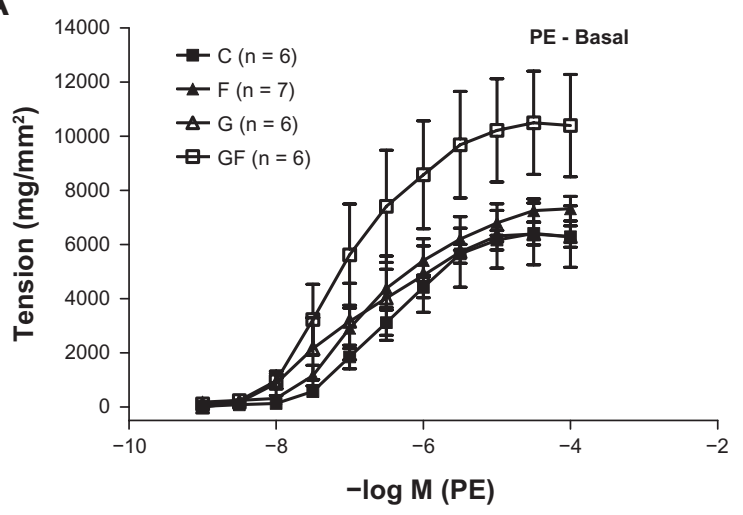

C

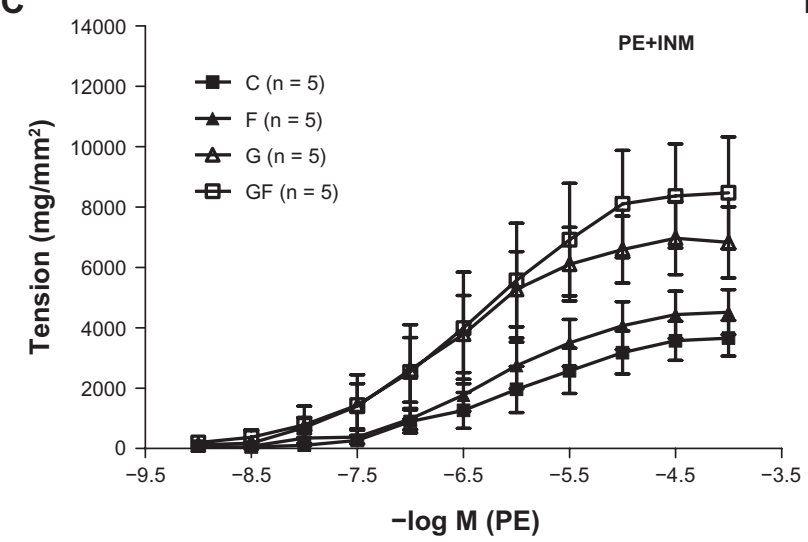

B

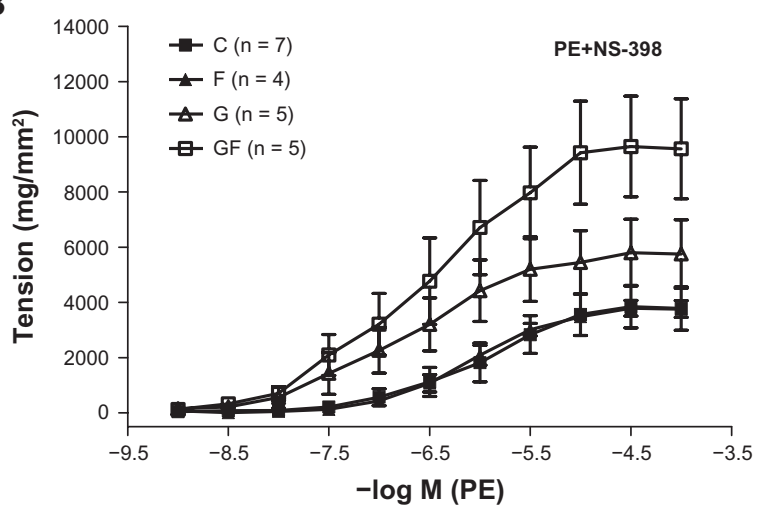

D

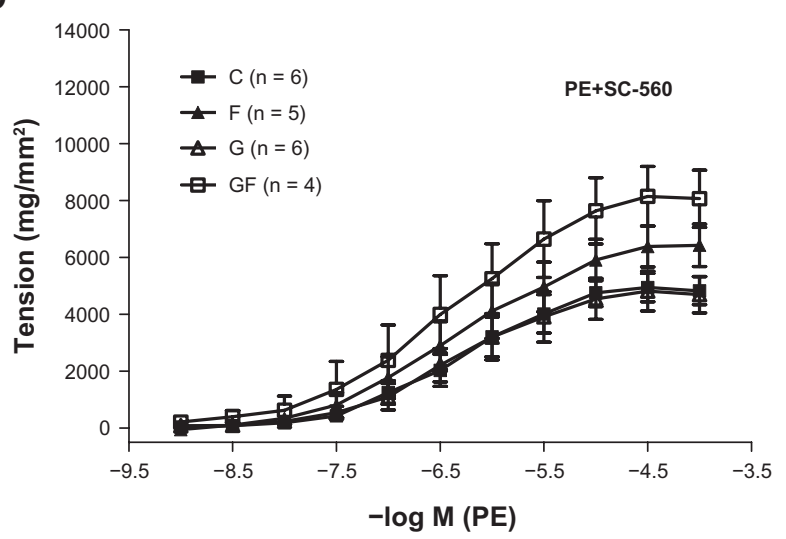

Figure 3 Contractile responses to phenylephrine (PE) in the superior mesenteric arteries (SMA) of intact and gonadectomized control and fructose-fed rats in the presence and absence of inhibitors. The 4 experimental groups were control (C), fructose-fed (F), gonadectomized (G), and gonadectomized fructose-fed (GF). A) Contractile responses to $\mathrm{PE}\left(10^{-9}-10^{-4} \mathrm{~mol} / \mathrm{L}\right)$ were unchanged in the absence of inhibitors. B) COX-2 selective inhibition by NS-398 ( $\left.10^{-6} \mathrm{M}\right)$ attenuated the responses to $\mathrm{PE}\left(10^{-9}-10^{-4} \mathrm{~mol} / \mathrm{L}\right)$ in the SMA of intact $(\mathrm{C}$ and $\mathrm{F})$ but not in gonadectomized (G and GF) rats. $* \mathrm{P}<0.05 \mathrm{G}$ and $\mathrm{GF}$ vs $\mathrm{C}$ and $\mathrm{F}$. C) Responses to $\mathrm{PE}\left(10^{-9}-10^{-4} \mathrm{~mol} / \mathrm{L}\right)$ were unaffected in the presence of the nonselective COX isoform inhibitor indomethacin $\left(10^{-5} \mathrm{M}\right)$. Both fructose and gonadectomy did not affect responses to PE subsequent to incubation with indomethacin. D) Responses to PE $\left(10^{-9}-10^{-4} \mathrm{~mol} / \mathrm{L}\right)$ were unchanged in both intact and gonadectomized control and fructose-fed rats following incubation with the COX-I selective inhibitor SC-560 (10-5 M). Values are in terms of $\mathrm{mg} / \mathrm{mm}^{2}$. " $\mathrm{n}$ " values are indicated on the graph. All values are presented as mean \pm SEM.

COX-2 expression in aortas incubated with PE. This would mimic the milieu present when we investigate the changes in vascular reactivity and help us confirm the effects of insulin resistance on the contributions of $\mathrm{COX}$ in mediating $\alpha$-adrenoceptor-stimulated vasoconstriction.

The availability of isoform-selective inhibitors of COX enabled us to look at the individual contributions of COX-1 and COX-2 to the vasculature. Thus, although COX-2 expression was unchanged (Figure 5A and 5B), both insulin resistance and testosterone promote the increased involvement of COX-2 in mediating vasoconstriction to PE in the aorta (Figure 4A-D; Table 3). Our findings are partly supported by Martorell et al who have shown improved relaxation to $\mathrm{ACh}$ in gonadectomized rat aorta along with concomitant increase in COX-2 expression and function. ${ }^{30}$

In the SMA, COX-2 may be regulated by testosterone alone and not by diet (Figure 3A-D; Table 2). COX-2 expression was unchanged in the SMA of intact and gonadectomized rats, which was similar to that observed following treatment with the androgen receptor blocker flutamide ${ }^{31}$ Furthermore, the improvement in endothelium-dependent relaxation upon COX inhibition (Figure 2) suggests a role in attenuating vasodilation and not in promoting vasoconstriction in the SMA of fructose-fed rats.

Although the degree of COX involvement is altered following insulin resistance, neither insulin resistance nor testosterone affected basal PE-induced contraction in both the aorta and SMA of F compared to controls (C) (Figures 3A and $4 \mathrm{~A}$ respectively). This is in agreement with previous work from our laboratory. ${ }^{3,32}$ While separate studies have shown upregulation in other vasoconstrictor systems such as endothelin-1, ${ }^{33,34}$ RAS, ${ }^{9,22}$ and sympathetic nervous systems ${ }^{35-37}$ along with parallel attenuation in $\mathrm{NO}$ and endothelium-dependent hyperpolarizing factor-dependent relaxation, ${ }^{3,38}$ the responses to a vasoconstrictor such as $\mathrm{PE}$ are unchanged in intact fructose-fed rats. In control intact and gonadectomized rat vessels, achievement of homeostasis may be attributed to a robust endothelial NO-dependent 


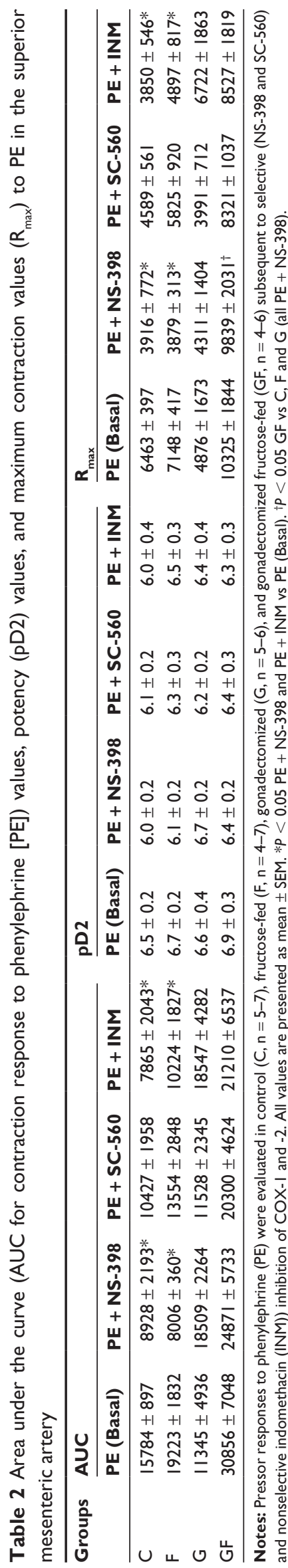

relaxation, which is impaired in fructose-fed rats. ${ }^{3,38}$ Therefore, we speculate that endothelium-independent mechanisms may be involved in preventing exaggerated vasoconstrictor responses to PE. These pathways, however, may not be salutary to the overall hemodynamics of the rats. NO produced by inducible NOS (iNOS) is one such endothelium-independent pathway present in the vascular smooth muscle which could mediate this phenomenon. An increase in oxidative stress is involved in diet-induced insulin resistance and elevation in blood pressure. ${ }^{39}$ iNOSdependent NO synthesis is increased following elevated oxidative stress due to insulin resistance. ${ }^{40}$ Interestingly, androgen also increases the susceptibility to oxidative stress, ${ }^{12}$ which if demonstrated in fructose-fed rats, could account for the testosterone-dependent differences in vascular reactivity. In principle, the potential increase in vasoconstriction may be neutralized by NO thus achieving homeostasis.

It would also be interesting to evaluate the position of COX-2 in the signaling pathways involved in PE-induced vasoconstriction. PE, by activating the $\alpha 1$ receptors, constricts blood vessels by activation of various mediators such as the RAS ${ }^{16}$ and COX-2. ${ }^{41}$ Interestingly, both mediators are regulated by testosterone $e^{4,7}$ and have been implicated in elevating blood pressure secondary to insulin resistance. ${ }^{3,4,42}$ However there is no direct evidence linking angiotensin-II and COX-2 in insulin-resistant conditions. Oxidative stress associated with the metabolic syndrome has been shown to increase the synthesis of vasoactive agents such as TXA2 (Figure 6) and eicosanoids, ${ }^{43}$ which suggests oxidative stress may play a key role in impairing vasoactive equilibrium associated with insulin resistance. However the increase in TXA2 levels in castrated fructosefed rats suggests that 1) there might be a feedback response to increase TXA2 as in the absence of testosterone, TXA2 was unable to exert its vasoconstrictor effects; 2 ) and also that COX-2 may be activating other testosterone-dependent pathways because had COX-2 stimulated TXA2 synthesis, gonadectomy would have decreased plasma TXA2 levels. This may be contrary to in vitro data, which show that testosterone increases TXA2 receptor density and expression in cultured rat vascular smooth muscle cells. ${ }^{44-47}$ Additional experiments are needed to tease out whether TXA2 synthesis and/or action is testosterone dependent.

It would also be interesting to study the potential interactions of COX-2 with other testosterone-dependent pathways such as the levels of the cytochrome P450 4A (Cyp4A) catalyzed arachidonic acid metabolite, 20-HETE, ${ }^{10}$ 
A

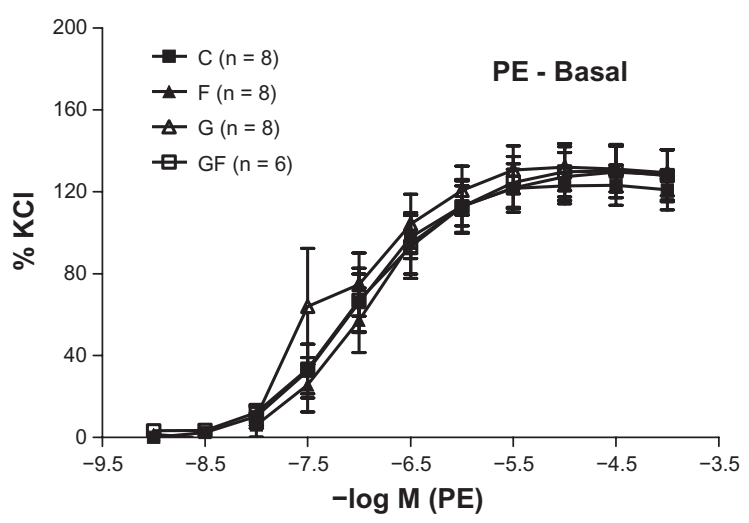

C

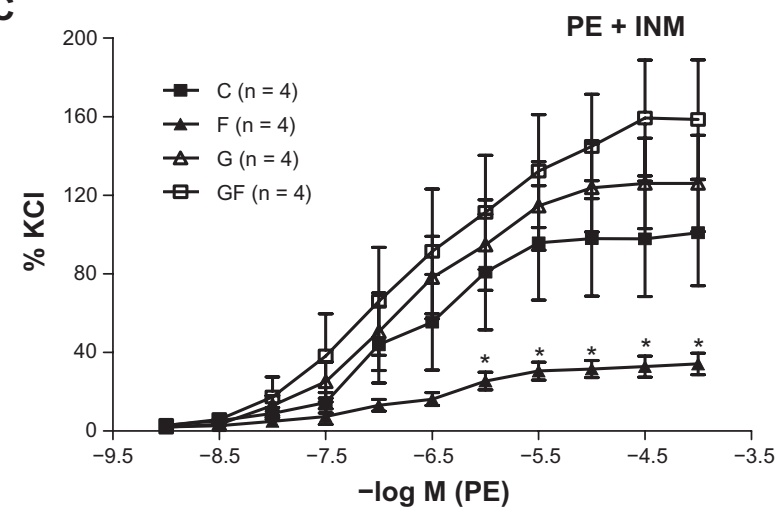

B

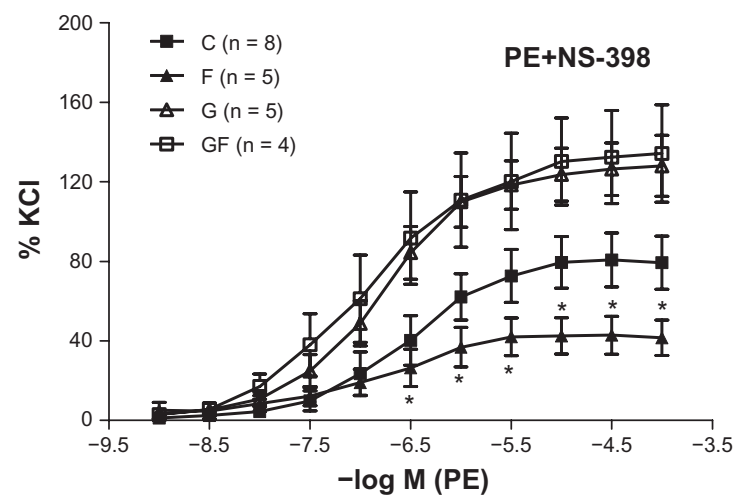

D

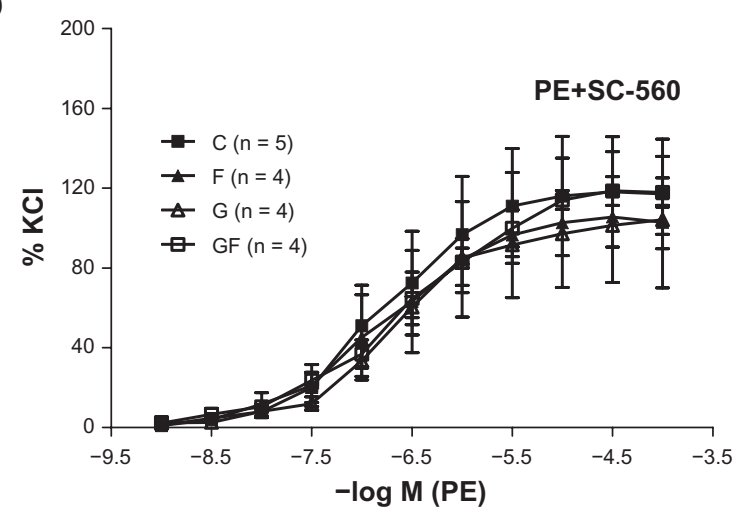

Figure 4 Contractile responses to phenylephrine (PE) in the aorta of intact and gonadectomized control and fructose-fed rats in the presence and absence of inhibitors. The 4 experimental groups were control and intact $(\mathrm{C})$, fructose-fed $(\mathrm{F})$, gonadectomized $(\mathrm{G})$, and gonadectomized fructose-fed (GF). A) Contractile responses to $\mathrm{PE}\left(\mathrm{I} 0^{-9}-10^{-4}\right.$ $\mathrm{mol} / \mathrm{L})$ were unchanged in the absence of inhibitors. B) COX-2 selective inhibition by NS-398 $\left(10^{-6} \mathrm{M}\right)$ attenuated the responses to $\mathrm{PE}\left(10^{-9}-10^{-4}\right.$ mol/L) in the aorta of intact $(\mathrm{C}$ and $\mathrm{F}$ ) but not in gonadectomized (G and GF) rats. ${ }^{*} P<0.05 \mathrm{G}$ and $\mathrm{GF}$ vs $\mathrm{C}$ and $\mathrm{F}$. C) Isoform nonselective COX inhibition by indomethacin (I0-5 M) attenuated the responses to $\mathrm{PE}\left(10^{-9}\right.$ to $\left.10^{-4} \mathrm{~mol} / \mathrm{L}\right)$ in intact ( $\mathrm{C}$ and $\mathrm{F}$ ) but not in gonadectomized (G and GF) rat aorta. $* P<0.05 \mathrm{G}$ and $\mathrm{GF}$ vs $\mathrm{C}$ and $\mathrm{F}$. D) Responses to $\mathrm{PE}$ ( $10^{-9}-10^{-4}$ $\mathrm{mol} / \mathrm{L}$ ) were unchanged in both intact and gonadectomized control and fructose-fed rat aorta in the presence of the selective COX-I inhibitor, SC-560 (I0-5 $\mathrm{M})$. Values are in terms of \% maximum response to $\mathrm{KCl}$. " $n$ " values are indicated on the graph. All values are presented as mean \pm SEM.

and RAS. ${ }^{14}$ Thus, although the effects of these systems have been investigated individually, sparse information exists about any interplay among these systems. We believe that the testosterone-dependent COX-2, RAS, and Cyp4A pathways could be interrelated and together contribute to endothelial dysfunction and hypertension.

In conclusion, the present work supports our earlier hypothesis that the vasoactive imbalance associated with endothelial dysfunction leads to attenuated endotheliumdependent relaxation and not elevated vasoconstriction. This is reflected in animal models of type 2 diabetes, such as Otsuka Long-Evans Tokushima fatty rats, where attenuated endothelial relaxation was ameliorated by blocking COX. ${ }^{48}$ Although individual vasoconstrictors may have been elevated subsequent to insulin resistance, their effects could be masked by endothelium-independent vasorelaxant pathways, which are activated as a compensatory mechanism. An important factor to consider is the time-dependent changes in contraction response to PE as the tissues were treated with various individual inhibitors over time. In the absence of COX inhibitors, the control tissues showed no change in contraction to $\mathrm{PE}$ over time, which indicates the responses to be consistent and reliable. COX-2 is selectively recruited in mediating vasoconstriction to $\mathrm{PE}$ and this phenomenon is regulated by testosterone. Inhibiting COX attenuates the synthesis of vasoconstrictor prostanoids thereby improving relaxation. This phenomenon, however, is tissue selective as the participation of COX in mediating contractile responses to $\mathrm{PE}$ following insulin resistance is elevated only in the aorta whereas in the SMA it is independent of diet. These findings warrant further study in order to identify the specific position of COX-catalyzed prostanoids in individual vasculature in addition to supporting the salutary effects of COX-2 inhibition in vivo in insulin resistance. ${ }^{19}$ Identifying molecular players in this phenomenon would contribute to a better understanding of the diverse vasoactive processes that are triggered by prostanoids. 

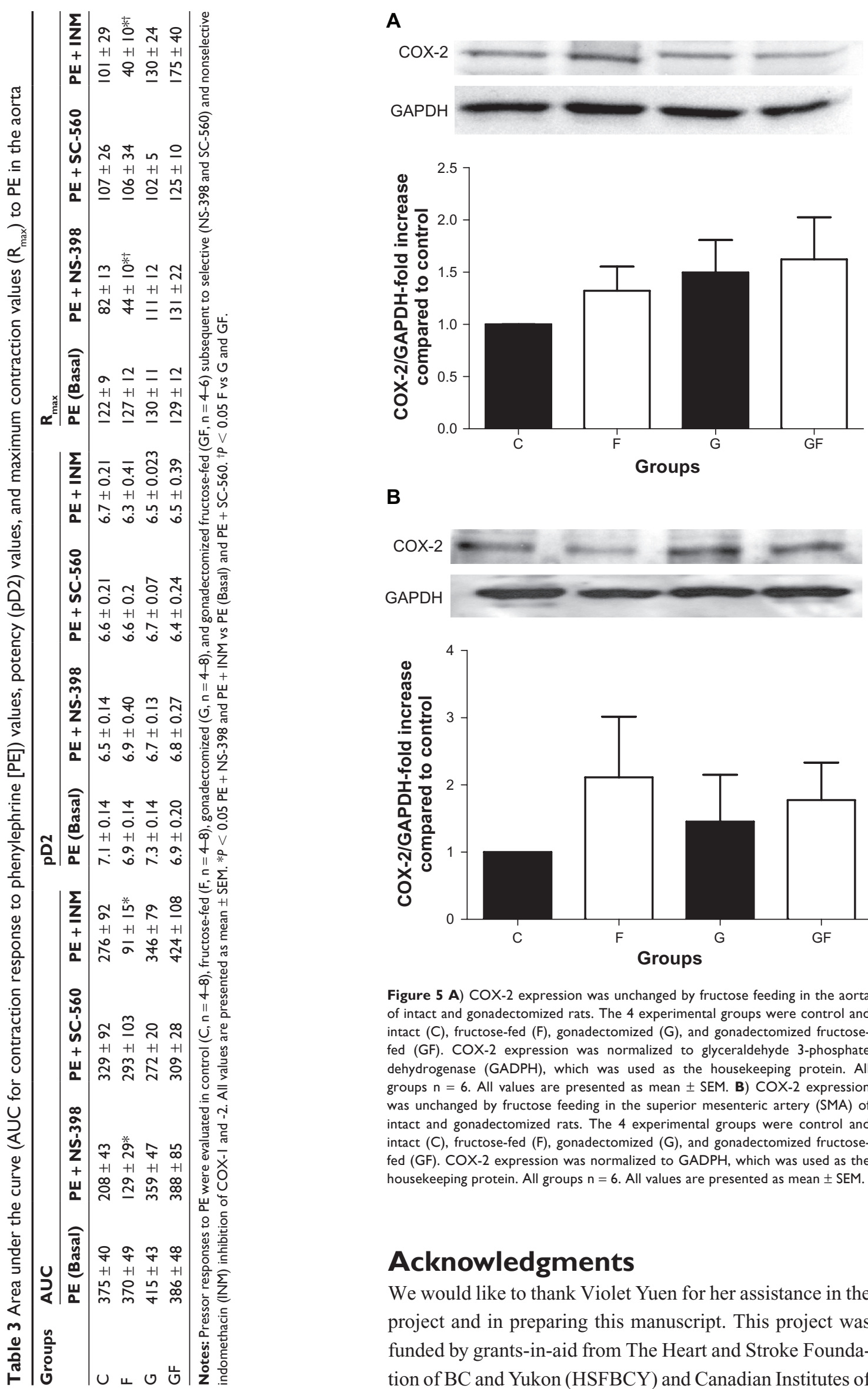

B
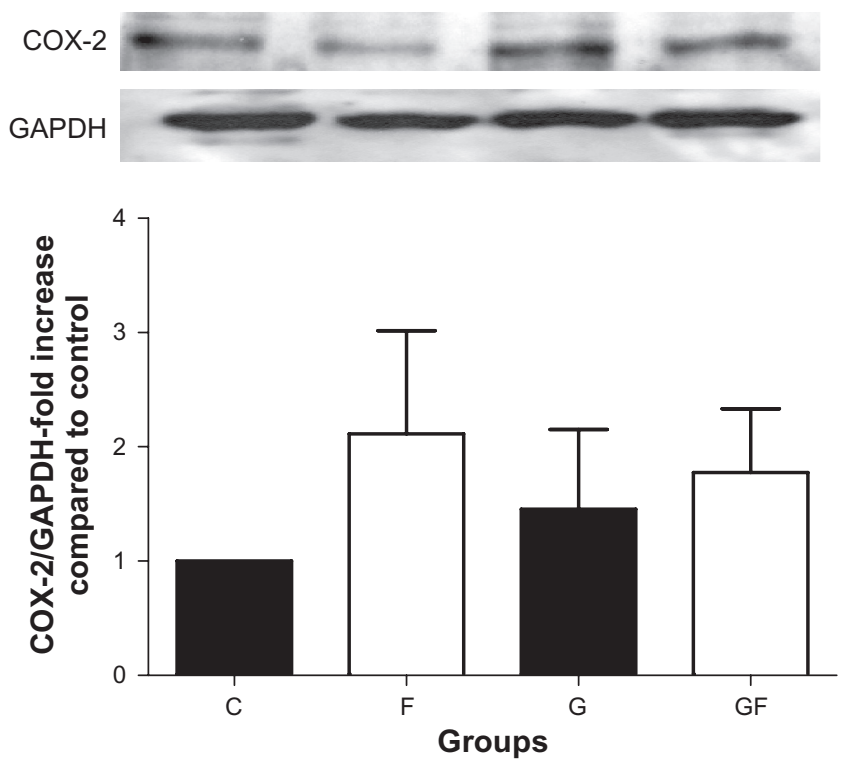

Figure 5 A) COX-2 expression was unchanged by fructose feeding in the aorta of intact and gonadectomized rats. The 4 experimental groups were control and intact $(C)$, fructose-fed $(F)$, gonadectomized $(G)$, and gonadectomized fructosefed (GF). COX-2 expression was normalized to glyceraldehyde 3-phosphate dehydrogenase (GADPH), which was used as the housekeeping protein. All groups $n=6$. All values are presented as mean \pm SEM. B) COX-2 expression was unchanged by fructose feeding in the superior mesenteric artery (SMA) of intact and gonadectomized rats. The 4 experimental groups were control and intact $(C)$, fructose-fed $(F)$, gonadectomized $(G)$, and gonadectomized fructosefed (GF). COX-2 expression was normalized to GADPH, which was used as the housekeeping protein. All groups $n=6$. All values are presented as mean \pm SEM.

\section{Acknowledgments}

We would like to thank Violet Yuen for her assistance in the project and in preparing this manuscript. This project was funded by grants-in-aid from The Heart and Stroke Foundation of BC and Yukon (HSFBCY) and Canadian Institutes of 


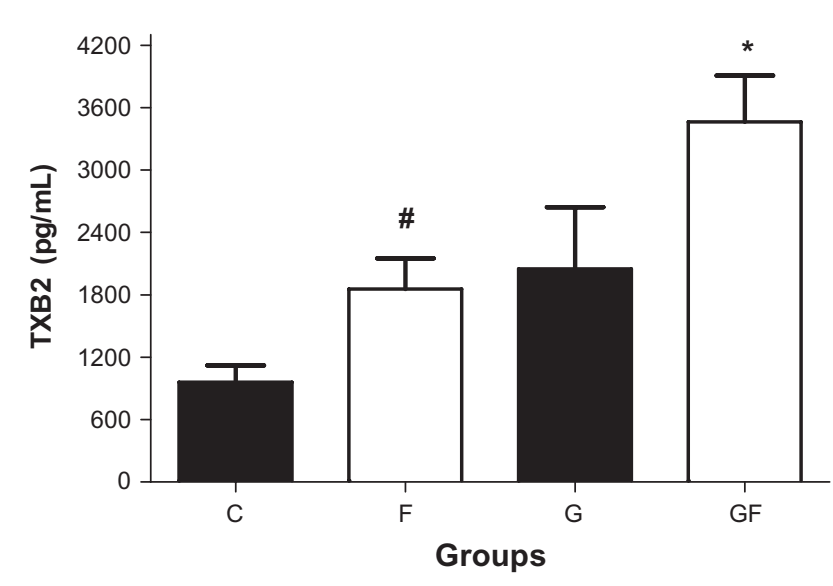

Figure 6 Gonadectomy and fructose feeding increased plasma thromboxane B2 (TXB2) levels. The 4 experimental groups were control and intact $(C)$, fructose-fed (F), gonadectomized $(G)$, and gonadectomized fructose-fed (GF). Thromboxane A2 was measured in terms of its stable metabolite TXB2 using an EIA kit.

Notes: All values are mean \pm SEM. $* P<0.05$ GF vs $C, F$ and G; ${ }^{*} P<0.05$ F vs $C$.

Health Research (CIHR-Priority announcement grant from the Institute of Gender and Health) to Dr. McNeill. Harish Vasudevan was funded by a Doctoral Research Award from the Heart and Stroke Foundation of Canada and a Senior Graduate Studentship from the Michael Smith Foundation for Health Research British Columbia, Canada.

\section{Disclosure}

The authors declare no conflicts of interest.

\section{References}

1. Hanna-Moussa A, Gardner MJ, Kurukulasuriya LR, Sowers JR. Dysglycemia/prediabetes and cardiovascular risk factors. Rev Cardiovasc Med. 2009;10(4):202-208.

2. Verma S, Bhanot S, Yao L, McNeill JH. Defective endotheliumdependent relaxation in fructose-hypertensive rats. Am J Hypertens. 1996; 9(4 Pt 1):370-376.

3. Vasudevan H, Nagareddy PR, McNeill JH. Gonadectomy prevents endothelial dysfunction in fructose-fed male rats, a factor contributing to the development of hypertension. Am J Physiol. 2006;291(6): H3058-H3064.

4. Song D, Arikawa E, Galipeau D, Battell M, McNeill JH. Androgens are necessary for the development of fructose-induced hypertension. Hypertension. 2004;43(3):667-672.

5. Chen YF, Naftilan AJ, Oparil S. Androgen-dependent angiotensinogen and renin messenger RNA expression in hypertensive rats. Hypertension. 1992;19(5):456-463.

6. Reckelhoff JF, Zhang H, Srivastava K. Gender differences in development of hypertension in spontaneously hypertensive rats: role of the renin-angiotensin system. Hypertension. 2000;35(1 Pt 2):480-483.

7. Sartori-Valinotti JC, Iliescu R, Yanes LL, Dorsett-Martin W, Reckelhoff JF. Sex differences in the pressor response to angiotensin II when the endogenous renin-angiotensin system is blocked. Hypertension. 2008;51(4):1170-1176.

8. Yanes LL, Sartori-Valinotti JC, Iliescu R, et al. Testosteronedependent hypertension and upregulation of intrarenal angiotensinogen in Dahl salt-sensitive rats. Am J Physiol Renal Physiol. 2009;296(4): F771-F779.
9. Hsieh PS, Tai YH, Loh CH, Shih KC, Cheng WT, Chu CH. Functional interaction of AT1 and AT2 receptors in fructose-induced insulin resistance and hypertension in rats. Metabolism. 2005;54(2): $157-164$.

10. Holla VR, Adas F, Imig JD, et al. Alterations in the regulation of androgen-sensitive Cyp 4a monooxygenases cause hypertension. Proc Natl Acad Sci U S A. 2001;98(9):5211-5216.

11. Ishizuka $\mathrm{T}$, Ito $\mathrm{O}$, Omata $\mathrm{K}$, Ito $\mathrm{S}$. Role of androgens in the renal production of 20-hydroxyeicosatetraenoic acid in spontaneously hypertensive rats. Nippon Jinzo Gakkai Shi. 2004;46(7):685-692.

12. Singh H, Cheng J, Deng H, et al. Vascular cytochrome P450 4A expression and 20-hydroxyeicosatetraenoic acid synthesis contribute to endothelial dysfunction in androgen-induced hypertension. Hypertension. 2007;50(1):123-129.

13. Skott O. Androgen-induced activation of 20-HETE production may contribute to gender differences in blood pressure regulation. Am JPhysiol Regul Integr Comp Physiol. 2003;284(4):R1053-R1054.

14. Reckelhoff JF, Zhang H, Srivastava K, Granger JP. Gender differences in hypertension in spontaneously hypertensive rats: role of androgens and androgen receptor Hypertension. 1999;34(4 Pt 2):920-923.

15. Vanhoutte PM. COX-1 and vascular disease. Clin Pharmacol Ther. 2009;86(2):212-215.

16. Alvarez Y, Perez-Giron JV, Hernanz R, et al. Losartan reduces the increased participation of cyclooxygenase-2-derived products in vascular responses of hypertensive rats. J Pharmacol Exp Ther. 2007;321(1):381-388.

17. Jiang J, Tran L, Vasudevan H, Xia Z, Yuen VG, McNeill JH. Endothelin-1 blockade prevents COX2 induction and TXA2 production in the fructose hypertensive rat. Can J Physiol Pharmacol. 2007;85(3-4): 422-429.

18. Galipeau D, Arikawa E, Sekirov I, McNeill JH. Chronic thromboxane synthase inhibition prevents fructose-induced hypertension. Hypertension. 2001;38(4):872-876.

19. Hsieh PS, Tsai HC, Kuo CH, et al. Selective COX2 inhibition improves whole body and muscular insulin resistance in fructose-fed rats. Eur J Clin Invest. 2008;38(11):812-819.

20. Puyo AM, Mayer MA, Giorgi S, Gomez AH, Peredo HA. Noradrenaline and angiotensin II modify vascular prostanoid release in fructose-fed hypertensive rats. Auton Autacoid Pharmacol. 2007;27(4):161-165.

21. Sugiyama T, Yoshimoto T, Sato R, et al. Endothelin-1 induces cyclooxygenase- 2 expression and generation of reactive oxygen species in endothelial cells. J Cardiovasc Pharmacol. 2004;44 Suppl 1:S332-S335.

22. Tran LT, Macleod KM, McNeill JH. Endothelin-1 modulates angiotensin II in the development of hypertension in fructose-fed rats. Mol Cell Biochem. 2009;325(1-2):89-97.

23. Hwang IS, Ho H, Hoffman BB, Reaven GM. Fructose-induced insulin resistance and hypertension in rats. Hypertension. 1987;10(5): 512-516.

24. Reaven GM, Ho H. Sugar-induced hypertension in Sprague-Dawley rats. Am J Hypertens. 1991;4(7 Pt 1):610-614.

25. Galipeau D, Verma S, McNeill JH. Female rats are protected against fructose-induced changes in metabolism and blood pressure. Am J Physiol. 2002;283(6):H2478-H2484.

26. Matsuda M, DeFronzo RA. Insulin sensitivity indices obtained from oral glucose tolerance testing: comparison with the euglycemic insulin clamp. Diabetes Care. 1999;22(9):1462-1470.

27. Verma S, Bhanot S, Yao L, McNeill JH. Vascular insulin resistance in fructose-hypertensive rats. Eur J Pharmacol. 1997;322(2-3):R1-R2.

28. Futaki N, Takahashi S, Yokoyama M, Arai I, Higuchi S, Otomo S. NS-398, a new anti-inflammatory agent, selectively inhibits prostaglandin $\mathrm{G} / \mathrm{H}$ synthase/cyclooxygenase (COX-2) activity in vitro. Prostaglandins. 1994;47(1):55-59.

29. Smith CJ, Zhang Y, Koboldt CM, et al. Pharmacological analysis of cyclooxygenase-1 in inflammation. Proc Natl Acad Sci U S A. 1998; 95(22):13313-13318. 
30. Martorell A, Blanco-Rivero J, Aras-Lopez R, Sagredo A, Balfagon G, Ferrer M. Orchidectomy increases the formation of prostanoids and modulates their role in the acetylcholine-induced relaxation in the rat aorta. Cardiovasc Res. 2008;77(3):590-599.

31. Vasudevan H. In Faculty of Pharmaceutical Sciences. University of British Columbia:Vancouver; 2009:1-151.

32. Verma S, Skarsgard P, Bhanot S, Yao L, Laher I, McNeill JH. Reactivity of mesenteric arteries from fructose hypertensive rats to endothelin-1. Am J Hypertens. 1997;10(9 Pt 1):1010-1019.

33. Lee DH, Lee JU, Kang DG, Paek YW, Chung DJ, Chung MY. Increased vascular endothelin-1 gene expression with unaltered nitric oxide synthase levels in fructose-induced hypertensive rats. Metabolism. 2001;50(1):74-78.

34. Miller AW, Tulbert C, Puskar M, Busija DW. Enhanced endothelin activity prevents vasodilation to insulin in insulin resistance. Hypertension. 2002;40(1):78-82.

35. Esler M, Straznicky N, Eikelis N, Masuo K, Lambert G, Lambert E. Mechanisms of sympathetic activation in obesity-related hypertension. Hypertension. 2006;48(5):787-796.

36. Straznicky NE, Eikelis N, Lambert EA, Esler MD. Mediators of sympathetic activation in metabolic syndrome obesity. Curr Hypertens Rep. 2008;10(6):440-447.

37. Verma S, Bhanot S, McNeill JH. Sympathectomy prevents fructoseinduced hyperinsulinemia and hypertension. Eur J Pharmacol. 1999; 373(2-3):R1-R4.

38. Katakam PV, Ujhelyi MR, Miller AW. EDHF-mediated relaxation is impaired in fructose-fed rats. J Cardiovasc Pharmacol. 1999; 34(3):461-467.

39. Song D, Hutchings S, Pang CC. Chronic N-acetylcysteine prevents fructose-induced insulin resistance and hypertension in rats. Eur J Pharmacol. 2005;508(1-3):205-210.
40. Wang H, Meng QH, Chang T, Wu L. Fructose-induced peroxynitrite production is mediated by methylglyoxal in vascular smooth muscle cells. Life Sci. 2006;79(26):2448-2454.

41. Alvarez Y, Briones AM, Balfagon G, Alonso MJ, Salaices M. Hypertension increases the participation of vasoconstrictor prostanoids from cyclooxygenase-2 in phenylephrine responses. J Hypertens. 2005; 23(4):767-777.

42. Nyby MD, Abedi K, Smutko V, Eslami P, Tuck ML. Vascular Angiotensin type 1 receptor expression is associated with vascular dysfunction, oxidative stress and inflammation in fructose-fed rats. Hypertens Res. 2007;30(5):451-457.

43. Tsai IJ, Croft KD, Mori TA, et al. 20-HETE and F2-isoprostanes in the metabolic syndrome: the effect of weight reduction. Free Radic Biol Med. 2009;46(2):263-270.

44. Higashiura K, Mathur RS, Halushka PV. Gender-related differences in androgen regulation of thromboxane A2 receptors in rat aortic smoothmuscle cells. J Cardiovasc Pharmacol. 1997;29(3):311-315.

45. Higashiura K, Blaney B, Morgan E, Mathur RS, Halushka PV. Inhibition of testosterone 5 alpha-reductase: evidence for tissue-specific regulation of thromboxane A2 receptors. J Pharmacolog Exp Ther. 1996;279(3):1386-1391.

46. Masuda A, Mathur R, Halushka PV. Testosterone increases thromboxane A2 receptors in cultured rat aortic smooth muscle cells. Circ Res. 1991;69(3):638-643.

47. Matsuda K, Mathur RS, Ullian ME, Halushka PV. Sex steroid regulation of thromboxane A2 receptors in cultured rat aortic smooth muscle cells. Prostaglandins.1995;49(3):183-196.

48. Matsumoto T, Kakami M, Noguchi E, Kobayashi T, Kamata K. Imbalance between endothelium-derived relaxing and contracting factors in mesenteric arteries from aged OLETF rats, a model of type 2 diabetes. Am J Physiol. 2007;293(3):H1480-H1490.
Journal of Experimental Pharmacology

\section{Publish your work in this journal}

The Journal of Experimental Pharmacology is an international, peerreviewed, open access journal publishing original research, reports, reviews and commentaries on all areas of laboratory and experimental pharmacology. The manuscript management system is completely online and includes a very quick and fair peer-review system.

\section{Dovepress}

Visit http://www.dovepress.com/testimonials.php to read real quotes from published authors. 